\title{
MONITORING THE AXIAL SHORTENING OF PRINCIPAL TOWER USING EMBEDDED DISTRIBUTED FIBRE OPTIC SENSORS
}

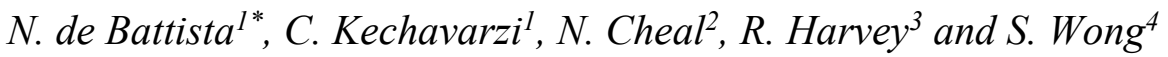 \\ ${ }^{1}$ Centre for Smart Infrastructure and Construction, Department of Engineering, University of Cambridge, Cambridge, UK \\ ${ }^{2}$ Multiplex Construction, London, UK \\ ${ }^{3}$ WSP Group, London, UK \\ ${ }^{4}$ Carey Group, London, UK \\ * Corresponding author
}

\begin{abstract}
Among the many challenges in the design and construction of high-rise buildings is the effect of differential axial shortening that the vertical load-bearing elements of the structure undergo. Axial shortening is time-dependent and very difficult to predict in advance. Therefore, it is essential for contractors to be able to measure accurately the amount of shortening that takes place in the constructed levels, in order to inform the setting out of new levels and the installation of façade cladding. We report on an innovative method that can be used to measure the axial shortening at any point along the height of individual concrete columns and walls, and at any point in time during construction. The monitoring system makes use of distributed strain and temperature measurements obtained using Brillouin-based techniques, from fibre optic cables that are embedded vertically in the structure during construction. This monitoring system was trialled for the first time at Principal Tower, a 50-storey reinforced concrete high-rise building constructed in London between 2016 and 2018. Two perimeter columns and two core walls were instrumented and monitored during and after construction, over a 20-month period. The unprecedented spatial and temporal resolution of the measured data enabled the project team to gain important insights into the nature of axial shortening. Of notable importance is the effect that variation in ambient temperature had on the shortening of individual members as well as on the rate of change of this shortening.
\end{abstract}

\section{Introduction}

The design and construction of tall buildings presents some formidable engineering challenges, one of which is axial shortening. Due to a combination of elastic (dead load) and inelastic (creep and shrinkage) loads, as well as transient environmental actions (thermal expansion and contraction), the columns and core walls of a tall building start shortening from the moment they are constructed. The amount by which each element shortens depends on several factors related to the geometry of the element, its material properties (including the amount of reinforcement in concrete members), its exposure and orientation, the load it supports, the construction sequence, and environmental factors (Jayasinghe \& Jayasena 2004, 2005). As such, axial shortening is time-dependent and each element shortens at different rates and by different amounts. This invariably gives rise to differential shortening across the footprint of the building, with the effect becoming more pronounced with increasing building height, as shortening differences accumulate from one level to the next (Kayvani 2014; Moragaspitiya et al. 2010).

The axial shortening of each member at specific construction milestones is predicted at the design stage using empirical methods (Fintel et al. 1986; Fintel \& Khan 1969; Moragaspitiya et al. 2010; Pan et al. 1993). However, these methods depend on several assumptions related to the factors mentioned above. Consequently, the construction process cannot rely solely on shortening estimates made by the consultant and the onus of accounting for axial shortening is placed on the contractor.

There are two main stages during the construction of a highrise building when axial shortening is a critical factor: when setting out the level of each slab relative to the datum, and when installing the façade cladding at each level. In both cases, an allowance has to be made for the amount of shortening that each column and wall is expected to experience in the future, such that at the moment of practical completion (completion of the whole project, including fit-out) the floor levels are as intended and the façade panels align, within tolerance (Baker et al. 2007). It is therefore important for the contractor to know how much shortening the building elements are experiencing during construction, in order to update the design estimates and adjust the pre-set levels of slabs and façade panels accordingly.

Traditionally, axial shortening of high-rise buildings is measured during construction by recording spot levels manually on a selection of columns and core locations. This is typically done once every few weeks, using laser surveying instruments or simply a steel tape to measure to a datum at ground level. These sporadic measurements can be used to infer axial shortening at specific points in time but do not provide any information about what is happening between measurements, and they cannot be used to measure the shortening profile along the height of the building. 
Occasionally, high-rise buildings have been instrumented with displacement monitoring systems, using strain gauges (Choi et al. 2013; Fragomeni et al. 2014; Kim \& Cho 2005; Russel \& Larson 1989; Xia et al. 2011) or fibre optic sensors (Glisic et al. 2013) mounted on the surface or embedded inside the building's structure. In each case, these monitoring systems made use of point sensors, measuring displacement at one or, at best, a limited number of levels. Although useful in providing a continuous measurement of shortening over time, these monitoring systems cannot provide a measure of the local member shortening at un-instrumented levels, or of the global shortening of the whole building

In order to address the spatial and temporal limitations of current techniques, a distributed fibre optic sensor (DFOS) axial shortening monitoring system (ASMS) was developed and trialled for the first time during the construction of Principal Tower in London, from September 2016 to April 2018. The monitoring system consists of fibre optic (FO) cables, which are continuously embedded within the columns and walls during construction. The strain and temperature along the embedded FO cables are measured regularly, at closely spaced intervals, using Brillouin optical scattering techniques, such as Brillouin optical time domain analysis (BOTDA). These measurements are then used to derive the axial shortening at each measurement point along the height of the instrumented elements, relative to a datum at the base of the building. The objectives of the current study were two-fold: (1) to trial the ASMS and develop it further into a robust monitoring tool for tall building construction, and (2) to gain a deeper insight into the axial shortening of tall buildings through the monitoring data.

\section{Axial shortening monitoring system at Principal Tower}

Principal Tower is a $163 \mathrm{~m}$-tall residential high-rise building, designed by Foster + Partners and situated between the City and Shoreditch areas of central London (Figure 1). It consists of two underground car park levels and apartments on 50 storeys above ground. The structure is made of reinforced concrete and comprises a central core, 12 perimeter columns, post-tensioned concrete floor slabs ranging from 200 to 225 $\mathrm{mm}$ in thickness, and outrigger walls at specific levels. Construction started in July 2016 and was completed in March 2018, with practical completion scheduled for mid-2019. Further details about the design and construction of Principal Tower are provided by de Battista et al. (2017a, 2017b).

The ASMS installed at Principal Tower is illustrated schematically in Figure 2, and can be described as having three parts: the embedded FO sensing cables, the FO routing cables, and the FO Brillouin spectrum analyser. The sensing part consists of FO cable pairs embedded in four vertical loadbearing members: two columns (referred to as C8 and C9) and two walls within the core (referred to as W1 and W2), which are located as shown in Figure 3. C8 and W2 extend up to level 43 (138 $\mathrm{m}$ above the ground floor) while C9 and W1 extend to the top of the building (161 $\mathrm{m}$ above the ground floor).
Figure 1 Principal Tower in April 2018, after construction was completed.

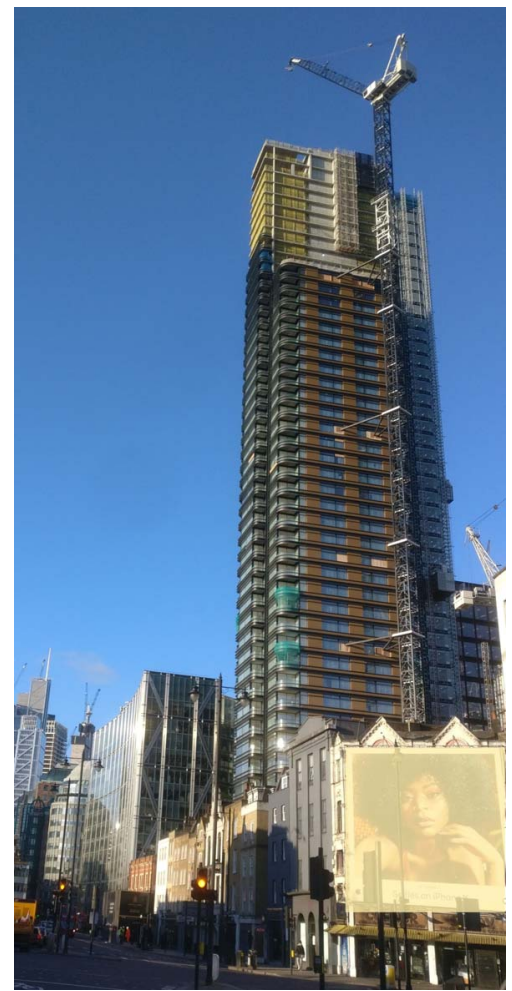

Figure 2 Schematic layout of the axial shortening monitoring system installed at Principal Tower, using distributed fibre optic sensors.

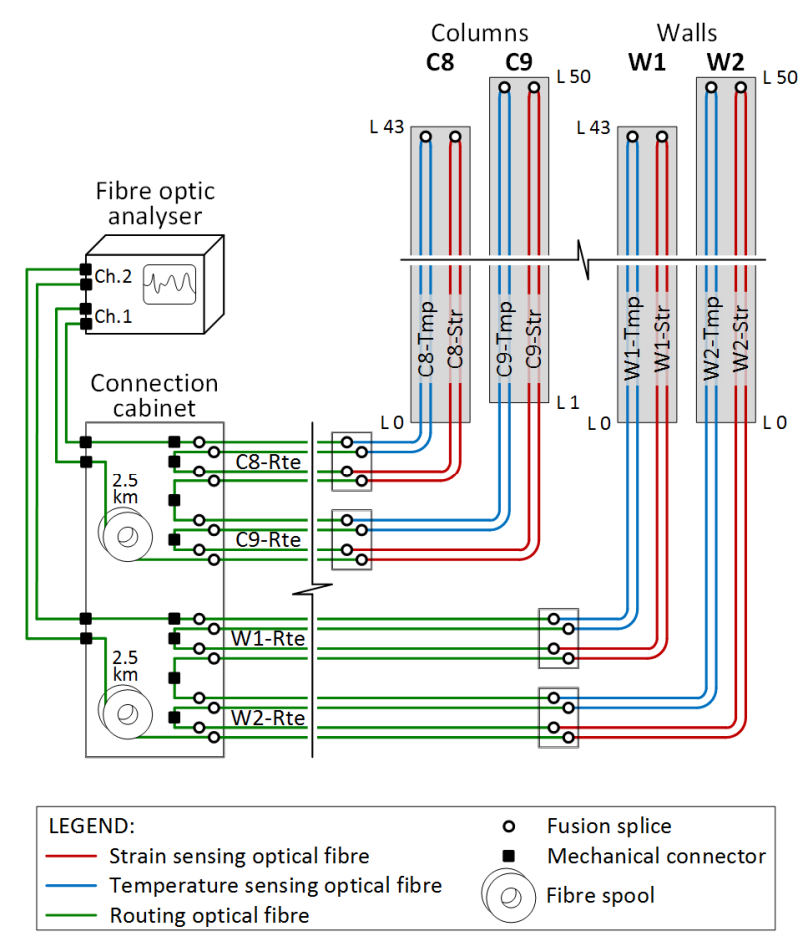


Figure 3 Layout of a typical floor at Principal Tower, with the location of the embedded fibre optic sensor cables circled and marked with dots.

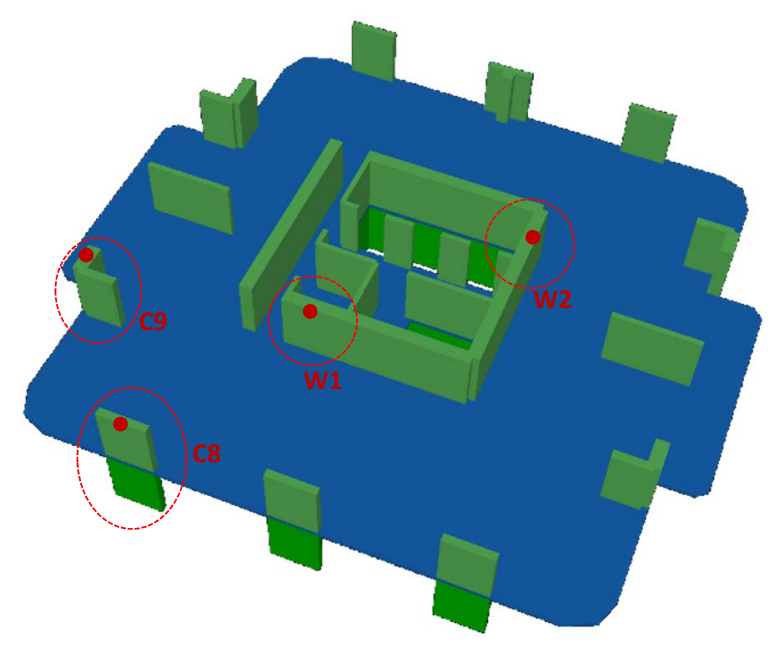

Each sensing cable pair comprises one FO cable for measuring strain and another for measuring temperature. The strain cable (Fujikura JBT-03813) contains four single mode optical fibre cores and two reinforcing steel strands, all tightly bonded to a nylon jacket, measuring $5.2 \times 1.3 \mathrm{~mm}$. The temperature cable (Excel 205-300) contains four single mode optical fibre cores loosely laid within a gel-filled tube, surrounded by reinforcing glass fibre strands and a thermoplastic jacket, measuring $6 \mathrm{~mm}$ in diameter.

\subsection{System installation}

Before construction began, each cable was pre-cut to have sufficient length to reach from the ground floor to the top of the element it was to be embedded in. Two of the four fibre cores in each cable were then fusion spliced to each other at one end of the cable, such that each cable formed a complete optical fibre loop within itself (i.e. a self-returning cable). Finally, the eight self-returning cables were wound on individual cable reels, with the spliced end on the inside of the reel and the bare end on the outside.

In August 2016, the bare ends of the FO cables were attached to the reinforcement of the instrumented elements just above the ground floor structural level, which was taken as being the datum level for axial shortening purposes. The two cables in each pair were cable tied securely to the bottom and top of the same vertical reinforcement bar, with the strain cable being pre-tensioned by hand. The FO cables were also held loosely to the reinforcement bar using cable ties, to keep them aligned vertically along the member. Every time that the construction progressed to a new level, the cables were un-reeled and the process was repeated to extend the cables to the top of the reinforcement of the new level. The construction operatives were trained on this cable installation process such that it was incorporated in the sequence of the contractor's steel-fixing works (Figure 4).
Figure 4 The fibre optic sensing cables being attached to the reinforcement of column $\mathrm{C} 8$ before being concreted.

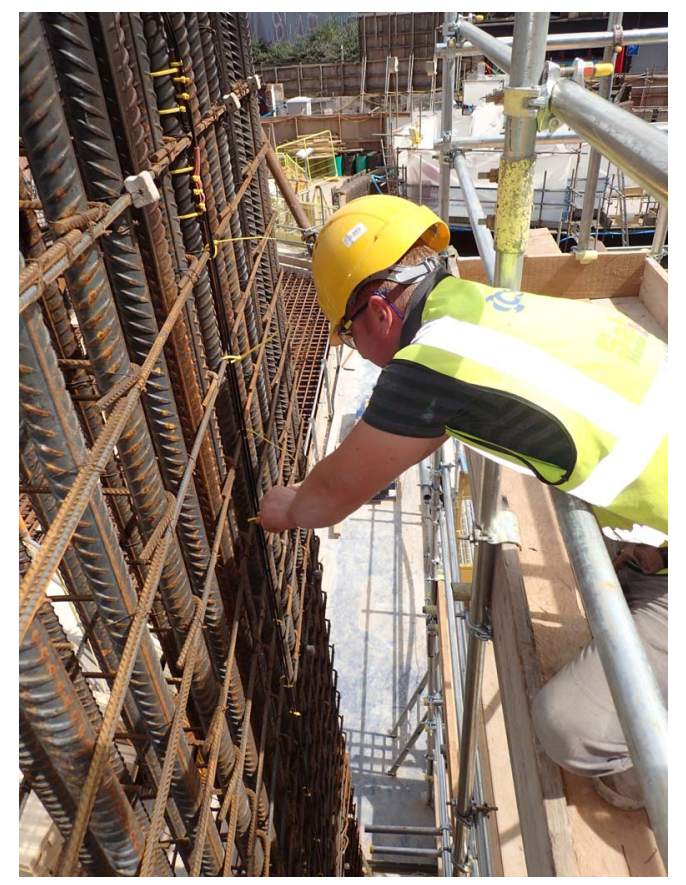

Before any of the instrumented members were concreted, the two self-returning fibres at the bare ends of each of the eight FO cables were fusion spliced to four-core FO routing cables (also Excel 205-300), with one routing cable per instrumented element, as shown in Figure 2. The role of the routing cables was to connect the sensing cables to the FO spectrum analyser, which was housed in a secure location inside a nearby building within the construction site. The routing cables were terminated in a connection cabinet next to the analyser, where the fibres in the routing cables were connected to each other using mechanical FC/APC connectors to form two separate circuits, one for the two columns and another for the two walls. The purpose of having independent circuits and of using connectors instead of fusion splices was to enable parts of the sensing system to be easily isolated and by-passed if any of the sensing cables were damaged.

\subsection{Monitoring}

The spectrum analyser used at Principal Tower was a DITEST STA-R two-channel Brillouin optical time domain analysis (BOTDA) analyser manufactured by Omnisens. It uses the technique of stimulated Brillouin scattering in a single-mode optical fibre to record the Brillouin frequency at discrete but closely spaced intervals along the fibre. The principles of Brillouin fibre optic distributed sensing are explained by Motil et al. (2016). Each of the FO circuits was connected to one of the analyser channels, such that automated measurements could be taken from each circuit in turn. 
Monitoring was started in September 2016, before the instrumented members were concreted at ground level. Measurements were taken twice every hour until April 2018, one month after construction was completed. The BOTDA measurement parameters listed in Table 1 were used during the monitoring. Each measurement recorded the peak Brillouin frequency, $v_{b}$, at $0.2 \mathrm{~m}$ intervals along the embedded strain and temperature cables. In total, this amounted to around 3000 measurement points of strain and temperature along the whole height of the building.

Table 1 Measurement parameters.

\begin{tabular}{ll}
\hline Parameter & Value \\
\hline Sampling interval & $0.2 \mathrm{~m}$ \\
Spatial resolution & $1.0 \mathrm{~m}$ \\
Measurement distance ${ }^{\mathrm{a}}$ & $2.10 \mathrm{~km}$ \\
Scanning frequency range & $10.5-11.0 \mathrm{GHz}$ \\
Scanning frequency step & $1 \mathrm{MHz}$ \\
Averaging over & 3000 pulses \\
Measurement time (per channel) & 8 to 9 min. \\
Measurement rate & once every 30 min \\
\hline${ }^{a}$ Initial measurement distance, excluding return fibre. This was reduced \\
when monitoring of C9 and W1 was stopped in July 2017.
\end{tabular}

\subsection{Data processing}

The measurement data were stored locally in the analyser's hard drive and also transferred automatically to a secure offsite server over a broadband Internet connection. One measurement for every hour was then post-processed to derive the change in peak Brillouin frequency, $\Delta v_{b}$, from the baseline measurement. This was done for each member at each level individually, with the baseline measurement being taken as the first measurement on the day following the concreting of that member (i.e. just after the following midnight). In cases where this measurement was not available (for example during system downtime), the baseline was taken as the first measurement of the first full day of monitoring following the concreting of the member.

From $\Delta v_{b, T}$ and $\Delta v_{b, \varepsilon}$ measured from the temperature and strain cables, respectively, the change in the fibres' (and hence the concrete's) temperature, $\Delta T$, and temperature-compensated strain, $\Delta \varepsilon$, were derived at each measurement point using the equations (Kechavarzi et al. 2016):

$\Delta v_{b, T}=\beta \Delta T$

and

$\Delta v_{b, \varepsilon}=C_{\varepsilon} \Delta \varepsilon+C_{T} \Delta T$

where $\beta$ is a lump coefficient obtained from laboratory calibration for the temperature cable $\left(\beta=1.07 \mathrm{MHz} /{ }^{\circ} \mathrm{C}\right)$ and $C_{\varepsilon}$ and $C_{T}$ are the Brillouin strain and temperature coefficients of the strain cable, respectively $\left(C_{\varepsilon}=480 \mathrm{MHz} / \%\right.$ and $\left.C_{T}=0.96 \mathrm{MHz} /{ }^{\circ} \mathrm{C}\right)$.
By assuming a coefficient of thermal expansion of the concrete, $\alpha=10 \times 10^{-6} /{ }^{\circ} \mathrm{C}$, the strain change was further subdivided into strain caused by thermal actions, $\Delta \varepsilon_{T}$, and strain caused by mechanical actions (elastic and inelastic), $\Delta \varepsilon_{S}$, using the equations

$\Delta \varepsilon=\Delta \varepsilon_{S}+\Delta \varepsilon_{T}$

and

$\Delta \varepsilon_{T}=\alpha \Delta T$

The total and mechanical axial displacement along the height of each member, relative to the base of that member, was derived by mathematical integration of the total $(\Delta \varepsilon)$ and mechanical $\left(\Delta \varepsilon_{S}\right)$ strain change, respectively. This was first done at each level individually, relative to the slab surface at that level. The displacements at the individual levels were then summed up for each member, to derive the cumulative axial displacement relative to the datum at ground level.

\section{Results and discussion}

The cumulative axial displacement measured from the instrumented elements during the first 12 months of construction is shown in Figure 5, with negative displacement indicating a shortening of the element. By the end of September 2017, the core and columns had been built up to level 39, the floor slabs up to level 37, and the façade had been clad up to level 19. Although the displacement was measured every $0.20 \mathrm{~m}$ along the height of the four elements, the data plots only show the average displacement of a $1 \mathrm{~m}$ section $(5$ data points) at the mid-height of each building level. The results discussed in this section relate to these average midheight displacement values.

The occasional periods with missing data that can be seen in Figure 5 are due to the monitoring having been stopped on one or more of the elements for maintenance to be carried out on the instrumentation, such as software updates or repairing of sensor cables that were accidentally damaged during installation. The monitoring on column C9 and wall W1 was stopped at the end of July 2017, when the sensor cables in these elements were damaged and could not be repaired. When this happened, construction had reached level 31.

\subsection{Differential shortening}

As expected, the columns shortened significantly more than the walls throughout the construction. The maximum shortening recorded during this 12 -month period was of $60.3 \mathrm{~mm}$, at level 38 of column C8 during the morning of $19^{\text {th }}$ September 2017. By contrast, the shortening recorded on wall W2 during the same morning was only $10.2 \mathrm{~mm}$. This highlights the importance of taking into account differential shortening between columns and walls when setting floor slab levels, in order to not end up with sloping floors when the building is completed. 
Figure 5 The total cumulative axial displacement (negative = shortening) of the instrumented columns and walls measured at the mid-height of every level (one plotted line per level) from the embedded fibre optic monitoring system at Principal Tower during the first 12 months of construction.
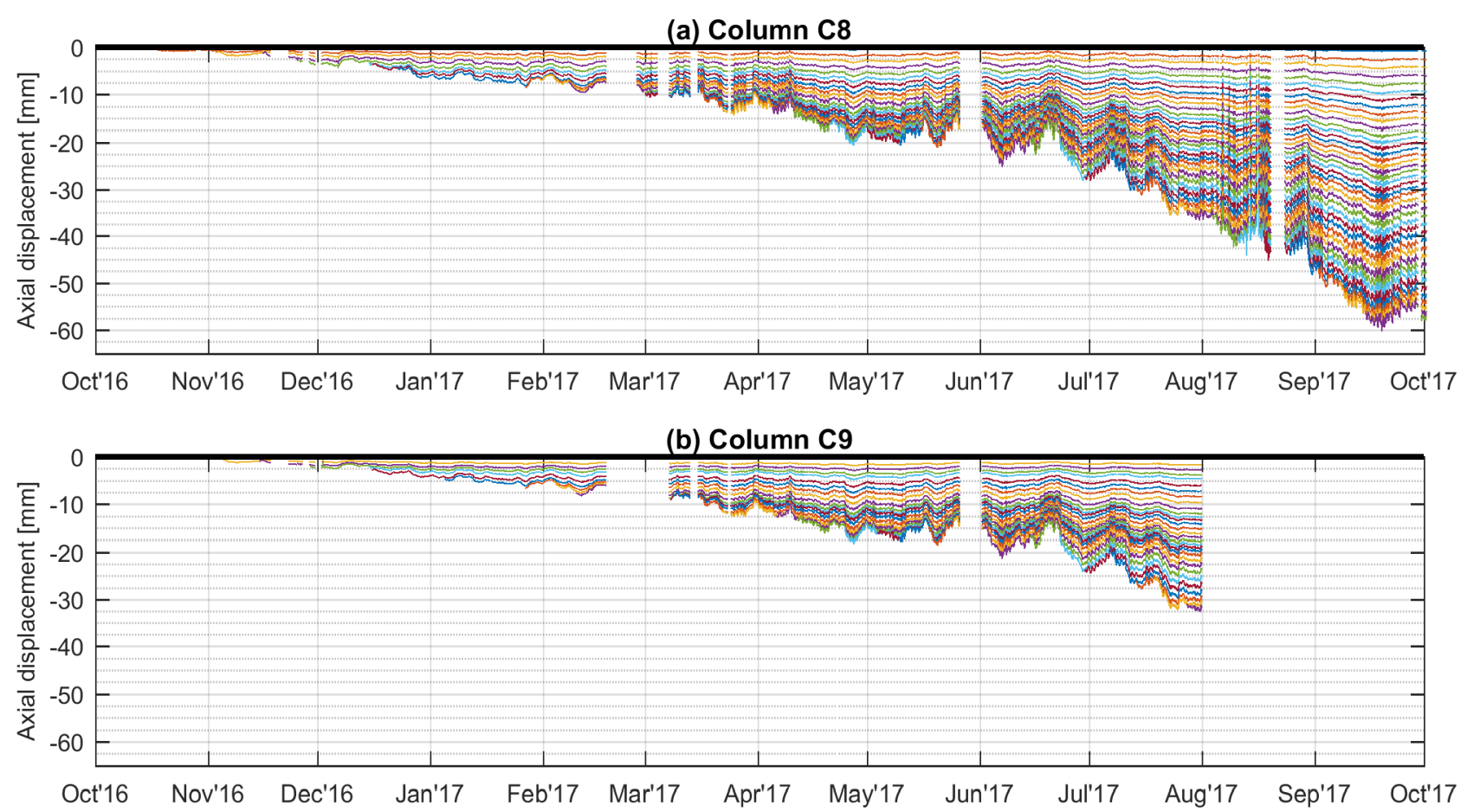

(c) Core wall W1

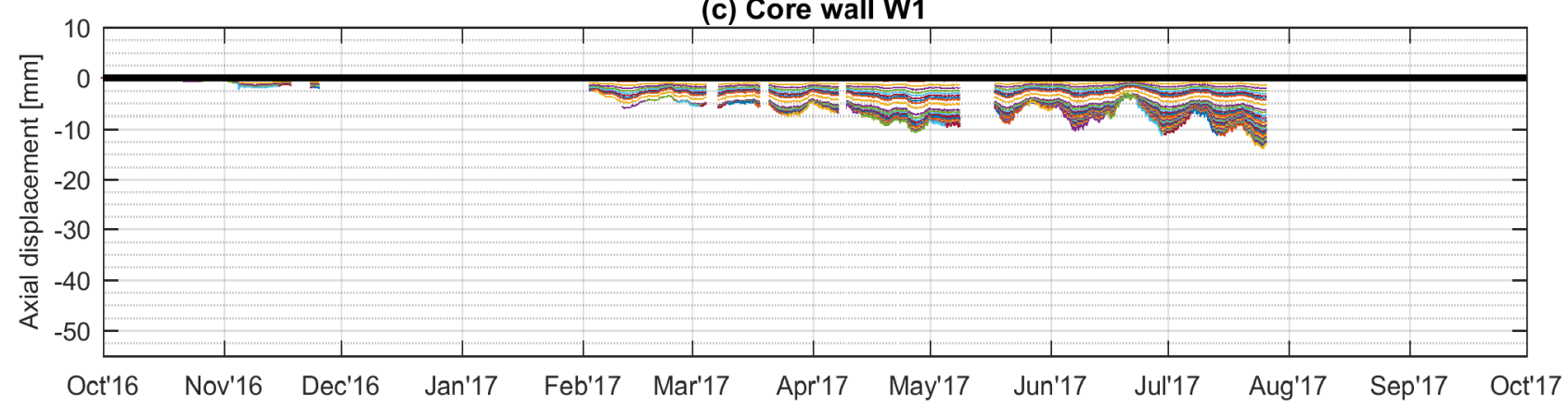

(d) Core wall W2

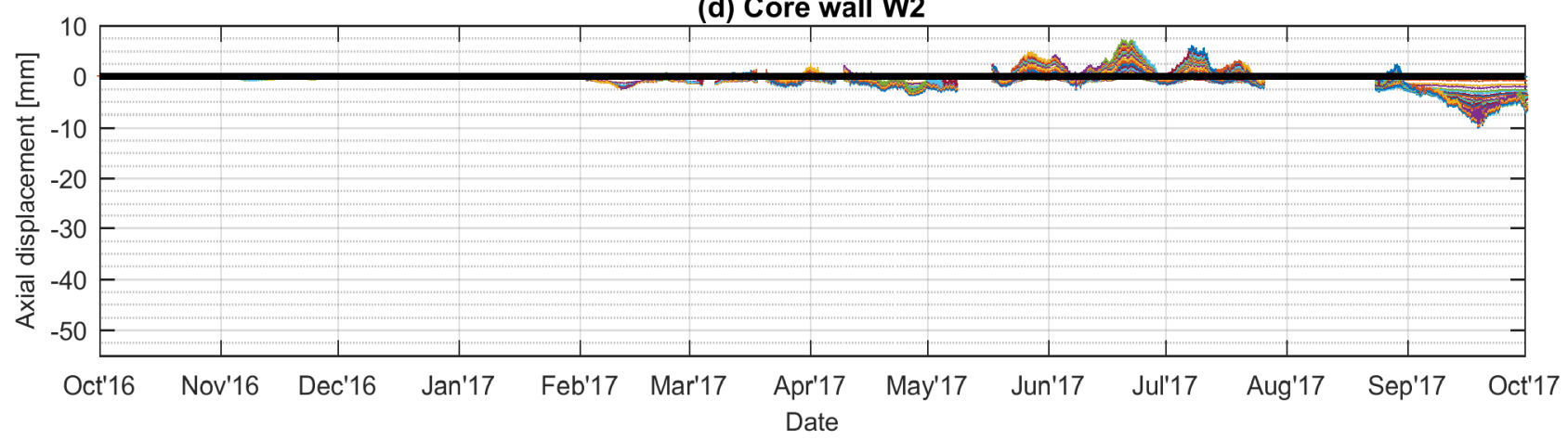


Differential shortening happens not only between the columns and core walls, but also between individual columns, as the plotted data confirm. At the end of July 2017, the maximum shortening recorded at level 31 on C8 was $36.6 \mathrm{~mm}$ while that on C9 was $32.6 \mathrm{~mm}$, approximately $11 \%$ less. This is due to $\mathrm{C} 8$ having a more slender profile, about $25 \%$ larger surface to area ratio than $\mathrm{C} 9$, and $15 \%$ less vertical reinforcement than C9, and despite the fact that C8 supports about $10 \%$ less dead load than C9.

The data also show that, although to a much lesser extent, core walls also undergo axial shortening that could add up to a significant amount. This is contrary to the assumption that is commonly made when carrying out shortening estimates, for which core walls are assumed to have negligible shortening. The maximum shortening recorded from any of the two walls during the first 12 months of construction was of $14.1 \mathrm{~mm}$, at level 30 of $\mathrm{W} 1$, on $25^{\text {th }}$ July 2017 , just before that wall stopped being monitored.

\subsection{Thermal effects}

In contrast to the theoretical evolution of axial shortening, which predicts that the shortening increases gradually throughout the construction, the axial shortening of Principal Tower was observed to fluctuate over time, following both diurnal and seasonal cycles. This is because the shortening of the columns and walls was significantly affected by thermal expansion and contraction.

The effect of thermal movement can be observed by comparing the total (measured) shortening with the mechanical shortening (i.e. the total shortening less the estimated thermal displacement, as explained in Section 2.3). An example of this is shown in Figure 6 for the two columns, during June and July 2017. During these 2 months, the maximum daily air temperature recorded in London (Heathrow Airport) reached highs of $32^{\circ} \mathrm{C}$ on $19^{\text {th }}$ June and $6^{\text {th }}$ July, with both days having 10 hours of sunshine (Source: www.weatheronline.co.uk). These dates correspond with the upward fluctuations observed in the total shortening of both columns (Figure 6a and c), as a result of the thermal expansion of the structure counteracting the elastic and inelastic shortening.

The minimum total shortening (i.e. when thermal expansion was at its maximum) recorded on these two days for C8 and C9 are shown in Table 2, together with the corresponding estimate of mechanical shortening and the percentage difference between the two. From these data, it can be seen that the axial shortening arising from mechanical actions was reduced by up to $29 \%$ due to the counteracting effect of thermal expansion.

Figure 6 The total (left side) and mechanical (right side) cumulative axial displacement (negative $=$ shortening) of the instrumented columns measured at the mid-height of every level (one plotted line per level) from the embedded fibre optic monitoring system at Principal Tower during June and July 2017.
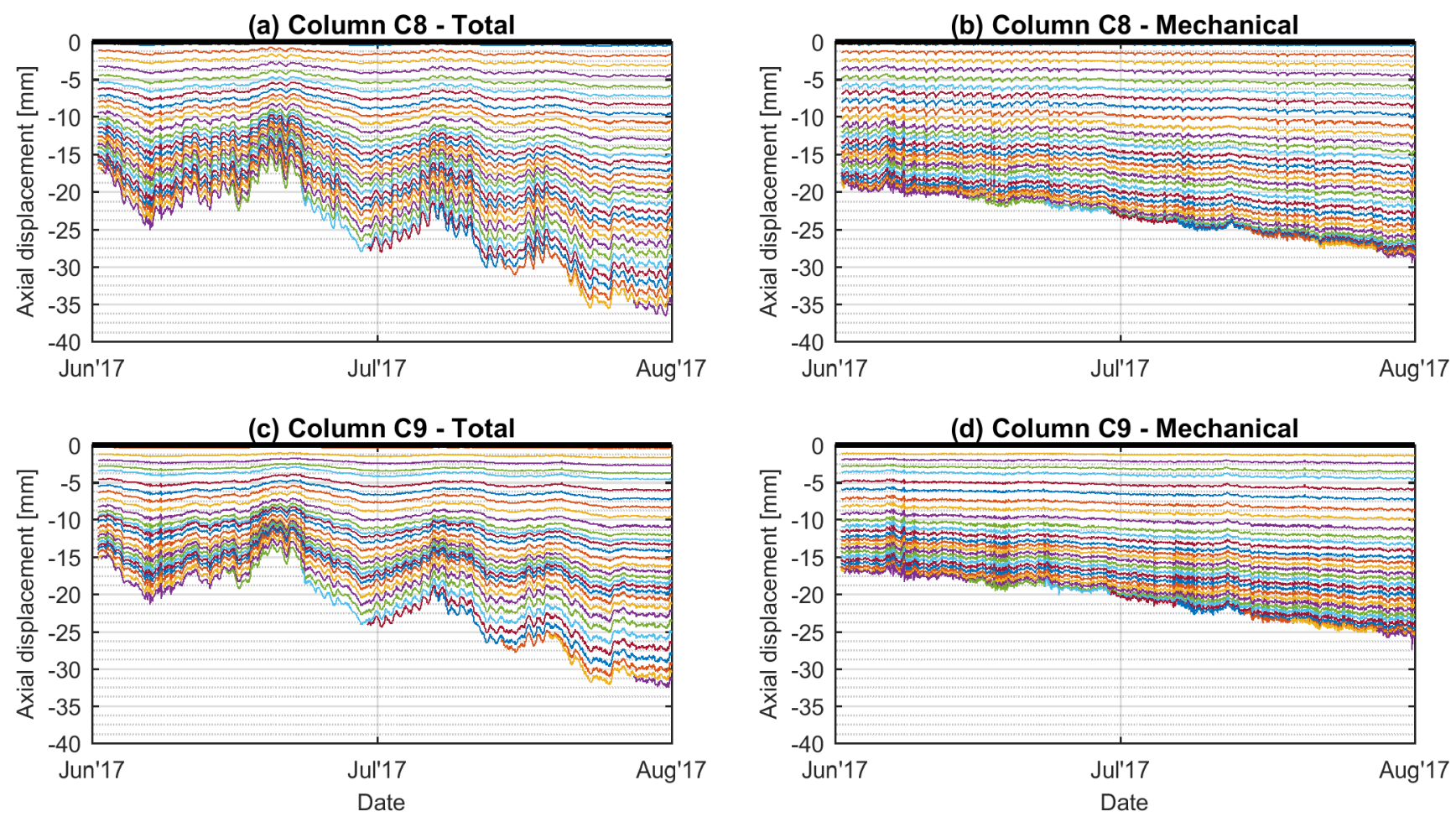
Table 2 Total and mechanical axial shortening recorded for columns C8 and C9, during $19^{\text {th }}$ June and $6^{\text {th }} \mathrm{July}$, at the time when the minimum total shortening was recorded.

\begin{tabular}{|c|c|c|c|c|}
\hline Date & Time & \multicolumn{2}{|c|}{ Column axial shortening (mm) } & Diff. $^{a}$ \\
\hline & & C8 Total, $\Delta \varepsilon$ & C8 Mech., $\Delta \varepsilon_{s}$ & \\
\hline 19 June & $17: 20$ & 14.9 & 20.9 & $29 \%$ \\
\hline 6 July & $20: 18$ & 21.2 & 23.5 & $10 \%$ \\
\hline & & C9 Total, $\Delta \varepsilon$ & C9 Mech., $\Delta \varepsilon_{s}$ & \\
\hline 19 June & $22: 14$ & 13.3 & 18.6 & $19 \%$ \\
\hline 6 July & $22: 15$ & 18.9 & 20.6 & $21 \%$ \\
\hline
\end{tabular}

Interestingly, on both occasions the minimum shortening of $\mathrm{C} 8$ was recorded a few hours earlier than that of C9. This is likely due to the fact that $\mathrm{C} 8$, which is on the south façade, was exposed to direct sunshine from about 10:00 to 18:30 while C9, which is on the west façade, was shaded until 14:00 and was then exposed to direct sunshine until sunset (around 21:00). Therefore $\mathrm{C} 8$ reached its maximum internal temperature earlier than $\mathrm{C}$.

These findings are significant in view of the fact that thermal effects and exposure to direct sunshine are not taken into account when axial shortening is estimated at the design stage. Therefore, relying too heavily on these estimates when presetting slab and façade levels could result in significant construction errors, particularly during periods of abnormally high or low temperatures. Besides the magnitude of the shortening, thermal effects also influence the rate at which the shortening increases or, at times, decreases. This is clear from the crests and troughs in the data plotted in Figure 6a and c, and further highlights the importance of measuring shortening continuously, such as with the DFOS system described in the paper.

\section{Conclusion}

The ability of an engineer to predict the axial shortening of a tall building is fundamental for safe and efficient design. These predictions are used by the contractor to pre-set column and core levels in order to ensure that floor levels are within acceptable tolerance when the building is completed. However, the behaviour of concrete under strain over time is notoriously difficult to predict because it depends on multiple variables, many of which are not known in advance. The only way to overcome this uncertainty is to measure the true axial shortening of the columns and walls, as the building is being constructed, in order to adjust the pre-set levels accordingly.

An innovative distributed fibre optic monitoring system has been developed to enable continuous measurements of axial shortening of columns and walls, along the entire height of a high-rise building, during construction. This axial shortening monitoring system (ASMS) relies on measurements of strain and temperature obtained by a Brillouin fibre optic spectrum analyser, at closely spaced intervals along optical fibres embedded within the structure of the building. The ASMS is intended for concrete and composite structures and can be adapted to monitor buildings of any height.

The ASMS was installed for the first time at Principal Tower, a 50-storey reinforced concrete high-rise building in central London. Two columns and two core walls were instrumented with fibre optic sensor cables, which were continuously embedded in the structure as construction progressed. The monitoring, which was carried out continuously over a 20month period, enabled the project engineers to measure axial shortening throughout the construction period with unprecedented precision and reliability.

The monitoring data were used to adjust the pre-set levels for the core, columns and unitised façade panels. This was necessary due to the amount of column differential shortening and the strong influence that thermal movement had on axial shortening. Thus, the construction was adapted to the real performance of the as-built structure, allowing the contractor to achieve better tolerances on the floor levels for internal fitout and reduce the risk of excessive movement in the façade joints.

Besides the immediate benefits for the construction process, the ASMS installed at Principal Tower has led to a number of observations, which were previously either not well understood or unknown. From the data, it is very clear that there was differential shortening between the columns as well as between the columns and walls. During the first 12 months of construction, the maximum shortening recorded from the columns was nearly six times more than that of the walls. Nevertheless, the monitoring data indicate that it might be imprudent to assume that the shortening of walls is negligible, as this might lead to an overestimation of the differential shortening between columns and walls.

The ASMS monitoring data have also shown that thermal expansion of the columns during periods of high ambient temperature reduced the shortening effect of loading, creep and shrinkage by up to $29 \%$. In addition, thermal actions also affected the rate of change of axial shortening, which the data showed was much faster than previously thought. If not catered for, these thermal effects can lead to the as-built concrete levels being out of tolerance. By having a continuous monitoring of axial shortening, the contractor is able to quantify the thermal effects on axial shortening and thus adjust the pre-set levels when necessary.

In conclusion, the trial of the ASMS at Principal Tower has highlighted the benefits of continuously measuring axial shortening during construction, as opposed to the traditional method of taking occasional spot measurements. Without being able to observe the time history and fluctuations in shortening of the different parts of the structure, the contractor runs the risk of costly errors in setting out slab and façade levels. 


\section{Acknowledgements}

The authors would like to acknowledge the contributions made by (listed in alphabetical order) Giuseppe Narcisio, Jason Shardelow, Paul Fidler and Peter Knott (CSIC); Diego PadillaPhilipps and Nello Petrioli (WSP Group); Mason Brown (Multiplex Construction); and the Careys site team of engineers and operatives, in particular Costel Niculcea (Careys).

This research has been made possible through funding under EPSRC grant EP/N021614/1 and Innovate UK grant 920035, as well as funding by WSP, Multiplex Construction and Careys.

\section{References}

Baker, W. F., Novak, L. C., Pawlikowski, J., Young, B., \& Korista, D. S. (2007). Creep and shrinkage and the design of supertall buildings - a case study: The Burj Dubai Tower. Special Publication, 246, 133-148.

Choi, S. W., Kim, Y., Kim, J. M., \& Park, H. S. (2013). Field monitoring of column shortenings in a high-rise building during construction. Sensors, 13(11), 14321-14338.

de Battista, N., Cheal, N., Harvey, R., \& Kechavarzi, C. (2017a). Monitoring the axial displacement of a high-rise building under construction using embedded distributed fibre optic sensors. In Proceedings of the 8th International Conference on Structural Health Monitoring of Intelligent Infrastructure (SHMII8), Brisbane, Australia.

de Battista, N., Harvey, R., \& Cheal, N. (2017b). Distributed fibre optic sensor system to measure the progressive axial shortening of a high-rise building during construction. In Proceedings of the 39th IABSE Symposium - Engineering the Future, Vancouver, BC, Canada.

Fintel, M., Ghosh, S. K., \& Iyengar, H. (1986). Column shortening in tall buildings - Prediction and compensation (No. EB108.01D), Skokie, IL.

Fintel, M., \& Khan, F. R. (1969). Effects of column creep and shrinkage in tall structures - Prediction of inelastic column shortening. ACI Journal Proceedings, 66(12). doi:10.14359/7444

Fragomeni, S., Whaikawa, H., Boonlualoah, S., \& Loo, Y. (2014). Axial shortening in an 80-storey concrete building. In S. Smith, ed., Proceedings of the 23rd Australasian Conference on the Mechanics of Structures and Materials (ACMSM23), Vol. II, Byron Bay, NSW, Australia, pp. 12311236.

Glisic, B., Inaudi, D., Lau, J. M., \& Fong, C. C. (2013). Tenyear monitoring of high-rise building columns using longgauge fiber optic sensors. Smart Materials and Structures, 22(5), 055030.

Jayasinghe, M. T. R., \& Jayasena, W. M. V. P. K. (2004). Effects of axial shortening of columns on design and construction of tall reinforced concrete buildings. Practice Periodical on Structural Design and Construction, 9(2), 7078.
Jayasinghe, M. T. R., \& Jayasena, W. M. V. P. K. (2005). Effect of relative humidity on absolute and differential shortening of columns and walls in multistory reinforced concrete buildings. Practice Periodical on Structural Design and Construction, 10(2), 88-97.

Kayvani, K. (2014). Design of high-rise buildings: past, present and future. In S. Smith, ed., Proceedings of the 23rd Australasian Conference on the Mechanics of Structures and Materials (ACMSM23), Byron Bay, NSW, Australia, pp. 9-12.

Kechavarzi, C., Soga, K., de Battista, N., Pelecanos, L., Elshafie, M., \& Mair, R. (2016). Distributed fibre optic strain sensing for monitoring civil infrastructure - A practical guide, London, UK: ICE Publishing.

Kim, H., \& Cho, S. (2005). Column shortening of concrete cores and composite columns in a tall building. The Structural Design of Tall and Special Buildings, 14(2), 175-190.

Moragaspitiya, H. N. P., Thambiratnam, D., Perera, N., \& Chan, T. (2010). A numerical method to quantify differential axial shortening in concrete buildings. Engineering Structures, 32(8), 2310-2317.

Motil, A., Bergman, A., \& Tur, M. (2016). State of the art of Brillouin fiber-optic distributed sensing. Optics \& Laser Technology, 78, 81-103.

Pan, L. B., Liu, P. C., \& Bakoss, S. L. (1993). Long-term shortening of concrete columns in tall buildings. Journal of Structural Engineering, 119(7), 2258-2262.

Russel, H. G., \& Larson, S. C. (1989). Thirteen years of deformations in Water Tower Place. Structural Journal, 86(2), 182-191.

Xia, Y., Ni, Y., Zhang, P., Liao, W., \& Ko, J. (2011). Stress development of a supertall structure during construction: Field monitoring and numerical analysis. Computer-Aided Civil and Infrastructure Engineering, 26(7), 542-559. 